\title{
An Investigation of the Effects of Some Safety System Modifications on the Safety of the HFIR
}

\author{
R. S. Stone \\ O. W. Burke
}




\section{DISCLAIMER}

This report was prepared as an account of work sponsored by an agency of the United States Government. Neither the United States Government nor any agency Thereof, nor any of their employees, makes any warranty, express or implied, or assumes any legal liability or responsibility for the accuracy, completeness, or usefulness of any information, apparatus, product, or process disclosed, or represents that its use would not infringe privately owned rights. Reference herein to any specific commercial product, process, or service by trade name, trademark, manufacturer, or otherwise does not necessarily constitute or imply its endorsement, recommendation, or favoring by the United States Government or any agency thereof. The views and opinions of authors expressed herein do not necessarily state or reflect those of the United States Government or any agency thereof. 


\section{DISCLAIMER}

Portions of this document may be illegible in electronic image products. Images are produced from the best available original document. 


\section{Printed in the United States of America. Available from National Technical Informatinn Servire. \\ U.S. Department of Commerce \\ 5285 Port Royal Road, Springfield, Virginia 22161 \\ Price: Printed Copy $\$ 4.50$; Microfiche $\$ 3.00$}

This report was prepared as an account of work sponsored by the United States Government. Neither the United States nor the Energy Research and Development Administration/United States Nuclear Regulatory Commission, nor any of their employees, nor any of their contractors, subcontractors, or their employees, makes any warranty, express or implied, or assumes any legal liability or responsibility for the accuracy, completeness or usefulness of any information, apparatus, product or process disclosed, or represents that its use would not infringe privately owned rights. 
ORNL/TM-5738

Contract No. W-7405-eng-26

INSTRUMENTATION AND CONTROLS DIVISION

AN INVESTIGATION OF THE EFFECTS OF SOME SAFETY SYSTEM MODIFICATIONS ON THE SAFETY OF THE HFIR
R. S. Stone
o. W. Burke

Date Published - June 1977

NOTICE: This document contains information of a preliminary nature. It is subject to revision or correction and therefore does not represent a final report.

OAK RIDGE NATIONAL LABORATORY

Oak Ridge, Tennessee 37830

operated by

UNION CARBIDE CORPORATION

for the

ENERGY RESEARCH AND DEVELOPMENT ADMINISTRATION

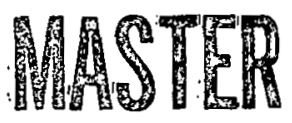

DISTRIBUTION OF THIS DOCUMENT IS UNLIMITED 
THIS PAGE

\section{WAS INTENTIONALLY. LEFT BLANK}




\begin{abstract}
A need for noise reduction in the HFIR has led to proposals to modify Modes 2 and 3 by adding smoothing capacitors to signal amplifiers and by removing the rate trip to lessen the effects of noise. Since both proposals can slow the safety system response; it must be demonstrated that the modified system still gives satisfactory protection against design basis accidents. Analog simulation was used to determine the effect of the proposed changes on the overall safety system response. In addition, many previously ruñ transient simulations were repeated using up-to-date values for system parameters. Safety system response with the proposed changes was found to give adequate protection against the most challenging combination of mishaps which are even marginally possible.
\end{abstract}


THIS PAGE

\section{WAS INTENTIONALLY \\ LEFT BLANK}


CONTENTS

$\underline{\text { Page }}$

1. INTRODUCTION . . . . . . . . . .......... . 1

2. MODEL DESCRIPTION . . . . . . . . . . . . . . . . 1

2.1 Reactor Kinetics Simulation .............. 2

2.2 Safety Rod Simulation . . . . . . . . . . . . 2

2.3 Heat Transfer Model ............... 4

3. CASE CONDITIONS AND RESUltS . . . . . . . . . . . . . . 5

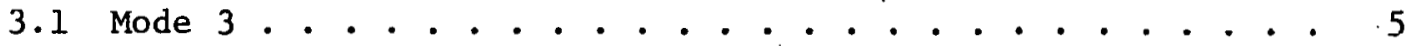

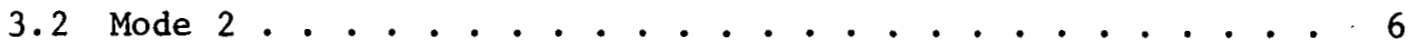

3.3 Modes 2 and 3 with Full Flow . . . . . . . . . . . . 7

3.4 Mode 1... . . . . . . . . . . . . . . . 7

4. CONCLUSIONS . . . . . . . . . . . . . . . . 10

4.1 The Startup Accident . . . . . . . . . . . . 10

4.2 The Optimum Void Insertion .............. . 10

APPENDIX A. COMPUTER MODEL DEVELOPMENT . . . . . . . . . . . 15

Al. Reactor Kinetics . . . . . . . . . . . . 15

A2. Safety Rod Drive System . . . . . . . . . . . . 23

A3. Heat Transfer . . . . . . . . . . . . . . 30

APPENDIX B. VARIATIONS OF PARAMETERS . . . . . . . . . . . . 39

REFERENCES . . . . . . . . . . . . . . . . . . . . . 41 


\section{INTRODUCTION}

A program of HFIR operation in low-power Modes 2 and 3 is currently of interest in connection with certain requirements of the technical specifications. However, at these low powers, noise pickup in the high sensitivity neutron sensor channels produces an unacceptable number of false scram signals. It has been suggested that, when in Modes 2 and 3, this problem be solved by placing feedback smoothing capacitors around the neutron flux signal amplifiers and by removing the rate trip. (The rate trip was originally intended for Mode 1 only, but it exists in Modes 2 and 3 as instrumentational carryover.)

The proposed smoothing capacitors would add some delay to the response time of the safety channels in Modes 2 and 3 , and it was the objective of this study to determine the effect of this proposed change on the overall safety response, adding appropriate simulation runs to those described elsewhere. 1

Projected changes to the HFIR safety system as used in Modes 2 and 3 have reopened the subject of safety response in all modes and under all conditions. As a consequence, much of the analog computer work previously reported ${ }^{1,2}$ was repeated, using some new conditions and up-to-date values for system parameters.

\section{MODEL DESCRIPTION}

The HFIR system was modeled on the ORNL analog computer. The model used for Mode 3 startup accidents had no coolant flow, but that used for void insertion accidents in all modes had provision for heat transfer to a flowing coolant. 


\subsection{Reactor Kinetics Simulation}

The model is similar to one used previously for optimum void transients, ${ }^{3}$ though differing in some details from that used for the HFIR accident analysis. 1 These differences are in the conservative direction, as is apparent from the results.

The conventional generation time reactor kinetics equations are used, assuming a single-region, one-group reactor:

$$
\Lambda \dot{P}=(\rho-\beta) P+\Lambda \sum_{1}^{3} \lambda_{i} X_{i},
$$

and

$$
\Lambda \lambda_{i} \dot{X}_{i}=\lambda_{i} \beta P-\lambda_{i}\left(\Lambda \lambda_{i} X_{i}\right)
$$

Two reduced groups of delayed neutrons are used, chosen to satisfy the asymptotic behavior of the six-group transfer function. A third group of "delayed neutrons" is added to represent those neutrons entering the core by way of the reflector. The change in "reactivity" as a result of rod motion is accomplished by changing $\beta_{3}$, the fractional value of the reflected neutron group. See Appendix, Sect. A1, for details of the kinetics simulation.

\subsection{Safety Rod Simulation}

The spring-loaded safety rods have an initial acceleration of $4 \mathrm{G}$. The acceleration is assumed to decrease linearly over the first 6 in. of travel to a value of $1 \mathrm{G}$ and to remain at $I \mathrm{G}$ for the remainder of the 20 in. of travel ( $G$ is the value of the acceleration due to gravity, 
$32.2 \mathrm{ft}\left(\mathrm{sec}^{2}\right)$. Letting $\mathrm{X}$ equal the safety rod displacement in inches, we can write:

$$
\frac{d^{2} x}{d t^{2}}=4 G-0.5 x G \quad(0 \leqslant x \leqslant 6 \text { in. })
$$

and

$$
\frac{d^{2} X}{d t^{2}}=G \quad(x>6 \text { in. })
$$

The change in reactivity generated by safety rod motion is described by a typical S-shaped curve of reactivity as a function of rod position. The change in reactivity per inch of rod travel was approximated as follows:

$$
\begin{array}{lc}
0.00058 \text { p/in. } & (0 \leqslant x \leqslant 2.5 \text { in. }) \\
0.00333 \text { p/in. } & (2.5<x \leqslant 12.1 \text { in. }) \\
0.000714 \text { p/in. } & (12.1<x \leqslant 20 \text { in. }) .
\end{array}
$$

The above rates approximate scramming three of the four plates from an initial fully withdrawn position corresponding to "end-op-core-11[e" conditions. Use of these rates for all cases is conservative, since the rod sensitivity is at its lowest.

The neutron flux signal was treated with a first-order lag circuit before it was used to trip the safety system. This lag circuit simulated the proposed use of a smoothing capacitor in the safety system to reduce the number of false scrams. In addition, a pure time 1 ag was used to simulate the rod magnet release time. The magnitude of each of these time lags was a variable in the model. 


\subsection{Heat Transfer Model}

For the Mode 3 (no flow) cases, no heat was removed from the modeled system. For cases having coolant flow, the model simulated heat transfer from the fuel plates to the flowing coolant.

For cases with heat removal by the flowing coolant, the heat removal equations for a typical region of the core are the following:

$$
C_{f} \frac{d T_{f}}{d t}=a P-h A\left(T_{f}-T_{w}\right),
$$

and

$$
C_{w} \frac{d T_{w}}{d t}=b P-\frac{C_{w}}{\tau}\left(T_{w}-T_{i n}\right)+h A\left(T_{f}-T_{w}\right),
$$

where

$$
\begin{aligned}
& \mathrm{C}_{\mathrm{f}}=\text { fuel plate heat capacity (total), Btu } /{ }^{\circ} \mathrm{F} \text {, } \\
& \mathrm{T}_{\mathrm{f}}=\text { average fuel temperature in the region, }{ }^{\circ} \mathrm{F}, \\
& a=\text { fraction of total power generated in the fuel, } \\
& P=\text { rate of total nuclear heat generation, } \\
& h=\text { overall heat transfer coefficient between the fuel and } \\
& \text { coolant, Btu } \sec ^{-1} \mathrm{ft}^{-2}{ }^{\circ} \mathrm{F}^{-1} \text {, } \\
& \mathrm{A}=\text { total heat transfer area of the region, } \mathrm{ft}^{2} \text {, } \\
& \mathrm{T}_{\mathrm{w}}=\text { average coolant temperature in the region, }{ }^{\circ} \mathrm{F} \text {, } \\
& \mathrm{C}_{\mathrm{w}}=\text { coolant heat capacity (total for the region), } \mathrm{Btu} /{ }^{\circ} \mathrm{F} \text {, } \\
& \mathrm{b}=\text { fraction of total power generated in the coolant, } \\
& \tau=\text { one-half the residence time of the coolant in this region } \\
& \text { of the core, sec, } \\
& \mathrm{T}_{\text {in }}=\text { coolant temperature at the region entrance, }{ }^{\circ} \mathrm{F} \text {. }
\end{aligned}
$$


Values for all vartables in these equations were obtalned from Table 4 of ref. 2, or they were deduced from the information in that table.

Equations (5) and (6) were used to develop heat transfer models of the average core, a "hot streak" region, and a "hot spot" region.

\section{CASE CONDITIONS AND RESULTS}

\subsection{Mode 3}

Mode 3 entails no-flow (head open) and very low power operation. Since there is no flow, void sweep-in is not possible, and the design basis reactivity insertion is the startup accident, that is, uncontrolled withdrawal of the shims. The entire simulated withdrawal is assumed to take place with the regulating cylinder at full speed, though this rate is actually only available for a 1-in. stroke. The nominal Mode 3 scram trip setting is $100 \mathrm{~kW}$; for the purposes of this study, the trip level was conservatively set at $130 \mathrm{~kW}$, the Limiting Safety System Setting (LSSS). Since rate trip removal is contemplated, no rate trip was activated. Heat transfer from the core was not allowed, and the temperature coefficient was assumed to be zero.

For rods initially positioned in the symmetrical-critical, $1 \% /$ in., high-worth center of the core ( $1 \%$ subcritical to start), startup accldents were aborted with negligible energy contents in the excursions. For example, the trip point was raised to $200 \mathrm{~kW}$ (twice the nominal value), the release time was made $25 \mathrm{msec}$ (at least twice the nominal value), and the smoothing time constant was set at $250 \mathrm{msec}$ (5-10 times the proposed value). With these conditions, the peak power was $8 \mathrm{MW}$; the integrated power was $243 \mathrm{kWsec}$. This represents a temperature rise in 
the core of only a few degrees $\left(6.45^{\circ} \mathrm{F}\right.$, assuming a core heat capacity of $\left.35.7 \mathrm{Btu} /{ }^{\circ} \mathrm{F}=37.7 \mathrm{kWsec} /{ }^{\circ} \mathrm{F}\right)$. With this trifling result from the extreme conditions assumed, no further symmetrical rod evaluations were examined.

The next Mode 3 case addressed was the asymmetrical rod condition. Three of the shim-safety rods are assumed fully withdrawn; from this smal1-worth position they will enter the core in a 3-of-4 scram. The regulating cylinder and the remaining shim-safety rod are withdrawn to achieve $1 \%$ subcriticality. The regulating cylinder and single shimsafety rod are then assumed to be withdrawn until a scram is actuated; the two controls together are assumed to add reactivity (or $\beta_{3}$ ) at the rate of $0.415 \% / \mathrm{sec}$.

The conditions for this run were: a trip point of $130 \mathrm{~kW}$, an unlatching time of $15 \mathrm{msec}$, and a smoothing time constant of $50 \mathrm{msec}$. These more realistic conditions resulted in a peak power of $2 \mathrm{MW}$ and an integrai energy input of $130 \mathrm{kWsec}$, corresponding to an adiabatic temperature rise of about $3.45^{\circ} \mathrm{F}$. Even in a $3-$ of -4 scram from the most disadvantageous position, the startup accident was of negligible consequence. The level scram with a $50-\mathrm{msec}$ smoothing time constant was clearly more than adequate.

\subsection{Mode 2}

In Mode 2 (low power operation with the head on and only pony motor coolant flow) the possibility of an optimum void insertion at a reduced flow rate must be taken into consideration. The potential void accident is capable of a far higher reactivity insertion rate than is the startup accident and, thus, is the design basis accident for Mode 2. The scram system is the same as for Mode 3, but the scram level is set at $3.25 \mathrm{MW}$, the LSSS for Mode 2. (Mode 2 trip point is nominally 2.5 MW.) 
The optimum void allows a maximum reactivity addition of $1.3 \%$. Inserted at a flow rate of about $14.7 \%$ of full flow, this amounts to a reactivity addition rate of $6.38 \% / \mathrm{sec}$. The input conditions and results of the Mode 2 void accident simulations with safety rod magnet release times of $10,15.2$, and $18 \mathrm{msec}$ are shown as case numbers 28,29 , and 30 In Table 1. The maximum fuel temperature reached at any point under any condition was $290^{\circ} \mathrm{F}$, far below a level for concern.

\subsection{Modes 2 and 3 with Full Flow}

Since it has been suggested that the coolant circulation pumps could be started in Modes 2 and 3, some simulations have been made using the starting conditions and safety system set points corresponding to Modes 2 and 3 , but with full coolant flow. For these cases the maximum void worth of $1.3 \%$ reactivity is inserted in $30 \mathrm{msec}$.

The input conditions and results are shown as cases 19-27 in Table 1 . In all these cases the heat transfer coefficient for the water film at any location was set equal to zero when the heat flux at that location reached the burnout level $\left(2.47 \times 10^{6} \mathrm{Btu} \mathrm{hr}^{-1} \mathrm{ft}^{-2}\right)$. In operation, this change only orcurred at the hot spot.

\subsection{Mode 1}

For the Mode 1 cases, the system is initially operating at a power level of $100 \mathrm{MW}$ and with full flow. The flow velocity used in previous design studies (reported in refs, 1 and 2) was $42 \mathrm{ft} / \mathrm{sec}$; after the system was operating, the flow velocity was discovered to be $51 \mathrm{ft} / \mathrm{sec}$. Also, the temperature coefficients of reactivity were different from those used in earlier studies. ${ }^{2}$ Since the model used in this latest 
Table 1. Iaput conditions and results

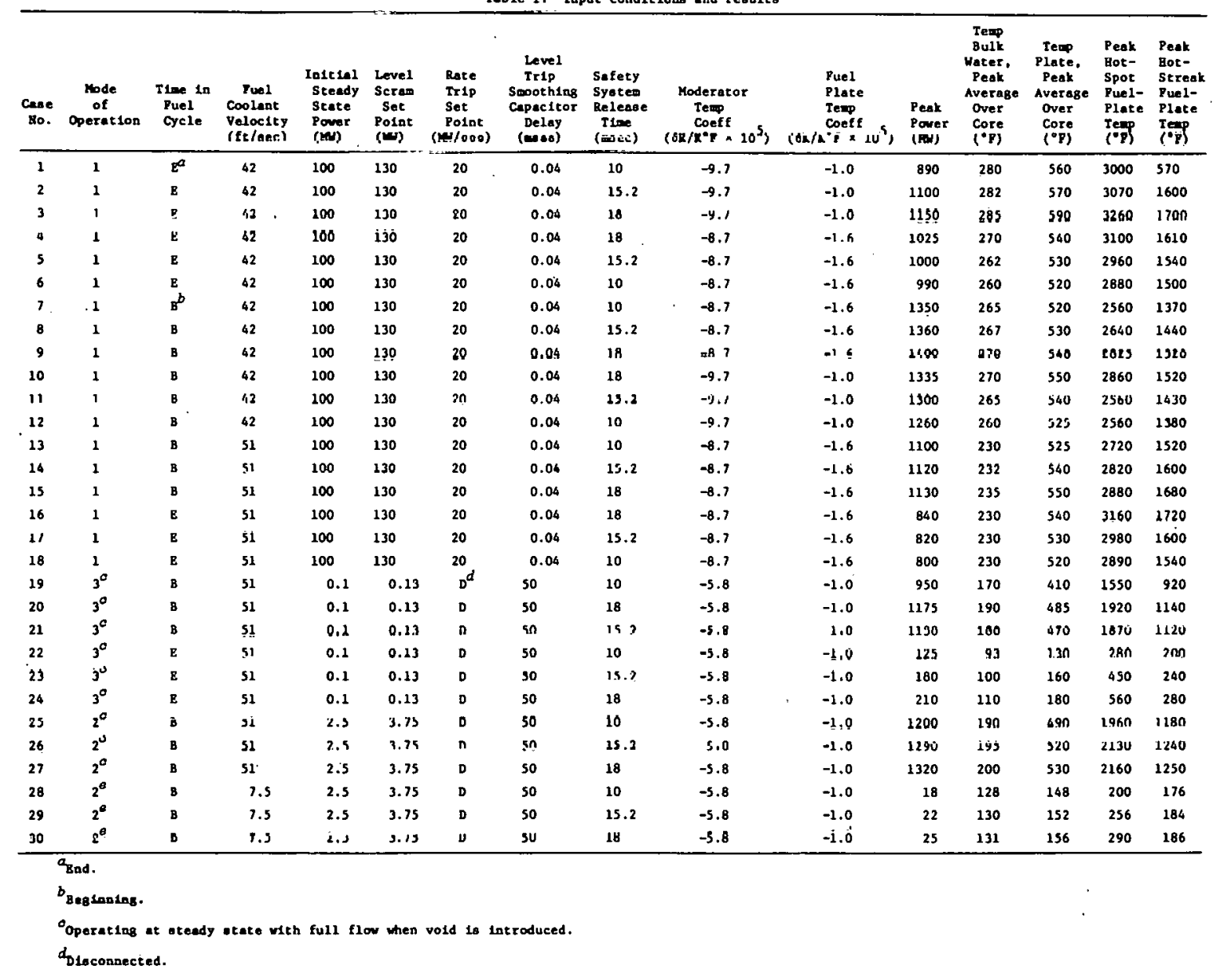

OOperating at oteady etete with 14.71 full tlov when vold is introduced. 
study differed In these respects from that used in earlier work, some cases were run using the previously reported values for flow rate and temperature coefficlents in order to obtain results for comparison. Cases 1-3 and 10-12 in Table 1 were run with the previously reported values. For these cases, the moderator coefficient of reactivity was $-9.7 \times 10^{-5} \rho /{ }^{\circ} \mathrm{F}$. For cases $4-9$ the flow velocity and the temperature coefficients of reactivity were as previously reported, ${ }^{2}$ namely $-8.7 \times 10^{-5} \rho /{ }^{\circ} \mathrm{F}$ for the moderator and $-1.6 \times 10^{-5} \rho /^{\circ} \mathrm{F}$ for the fuel. For cases 13-18 the flow velocity was the new value of $51 \mathrm{ft} / \mathrm{sec}$, and the temperature coefficients of reactivity were as reported in ref. 2 . The input conditions and results for the above cases are shown in Table 1 .

In this study, the heat transfer coefficient for the water film at the hot spot was set equal to zero when the heat flux at the hot spot reached the burnout level $\left(2.47 \times 10^{6} \mathrm{Btu} \mathrm{hr}^{-1} \mathrm{ft}^{-2}\right)$.

Since there was no provision in the model for the fuel plates to absorb the heat of fusion when the melting point temperature was reached, all temperatures above the melting point were not true temperatures. However, the degree of melting can be approximated by multiplying the amount of "temperature" rise above the melting point by the ratio of the fuel plate heat capacity to its heat of fusion. An indicated temperature of about $1900^{\circ} \mathrm{F}$ riorresponds to $100 \%$ of the heat of fusion. 


\section{CONCLUS IONS}

\subsection{The Startup Accident}

The startup accident is examined in sect. 3.1. This accident commands reactivity addition rates so far below the reactivity removal capabilities of the safety system as to lead to transients of trivial magnitude under the most pessimistic conditions. The reactor control and safety systems were, of course, designed with this result as an objective.

\subsection{The Optimum Void Insertion}

The optimum void accident is examined in Sects. $3.2,3.3$, and 3.4 , Results for a wide variety of conditions are presented in Table 1.

Mode 3 is.provided in order to permit operation without coolant flow, and, hence, under design conditions it has no mechanism for the rapid insertion of a void. Mode 2 is designed for operation with greatly reduced coolant flow (from pony motors only). At $14.7 \%$ of full flow, the opt1mum void insertion is accomplished in something over $200 \mathrm{msec}$. However, even with the added 50-msec smoothing time constant and with an unlatching time as long as $18 \mathrm{msec}$, the safety system has the reactivity turned downward within $140 \mathrm{msec}$. Since the maximum reactivity reached is less than a dollar, the resulting transient is correspondingly mild. 3ee Fig. 1.

For Modes 2 and 3 to exhibit void induced transients approaching those possible in Mode 1, Modes 2 and 3 must be given a coolant flow rate equal to that used in Mode 1 . Section 3.3 describes simulations where such cases were examined. Here, compensating differences exist 


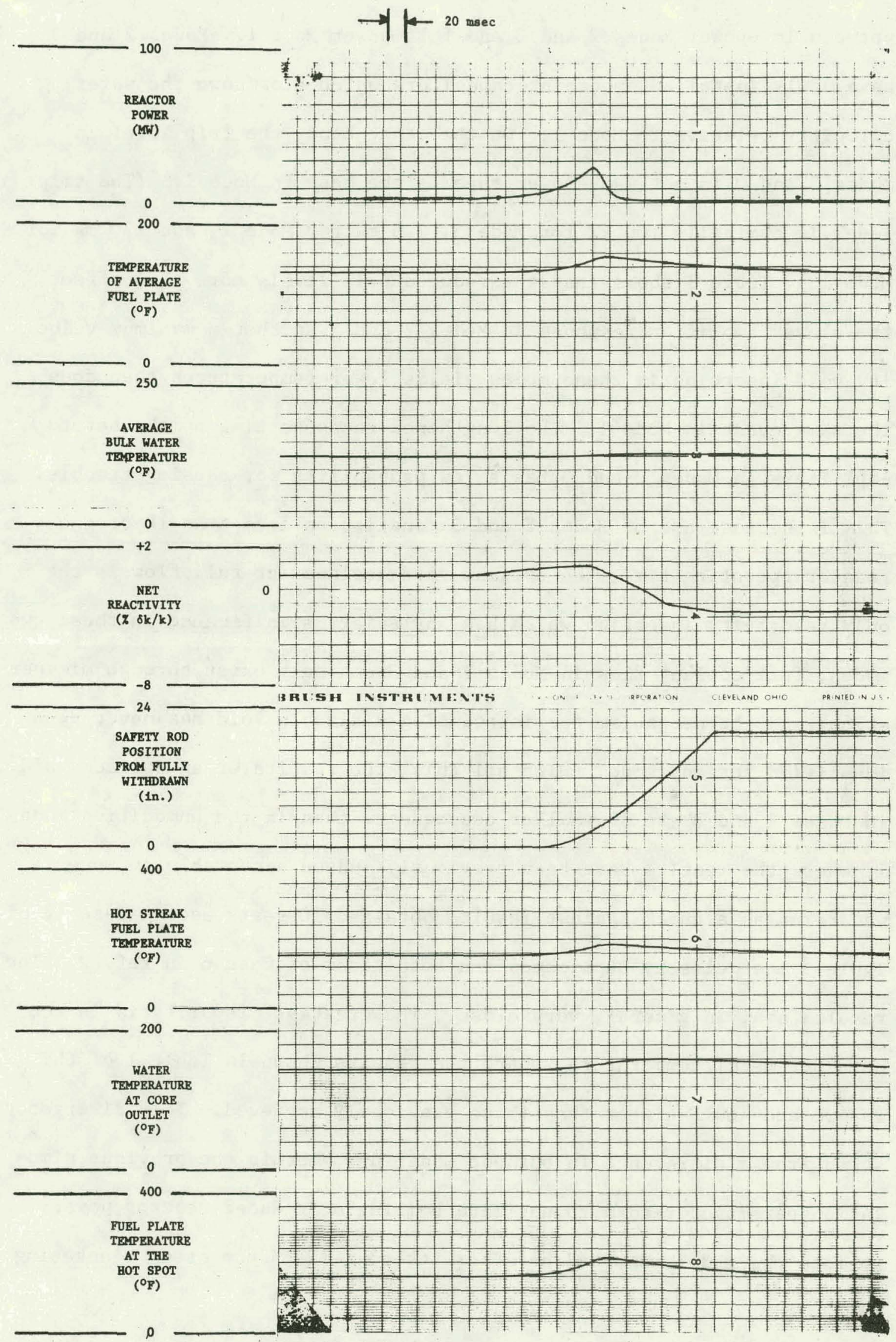

Fig. 1. Analog computer output for Case No. 30 described in Table 1. 
between low-power Modes 2 and 3 and full-power Mode 1 . Modes 2 and 3 have newly installed smoothing capacitors which slow down the safety circuitry relative to Mode 1 . On the other hand, the trip level in Modes 2 and 3 is set much lower than is the case in Mode 1. (The trip level is nominally $100 \mathrm{~kW}$ for Mode 3, $2.5 \mathrm{MW}$ for Mode 2, and $130 \mathrm{MW}$ for Mode 1.) Table 1 shows that the reduced trip levels more than offset the slower amplifier response in Modes 2 and 3 so that a maximum velocity void insertion in these modes yields 1 nwer temperatures than does the same event in Mode 1. The lengthened response time of the safety amplifiers in Modes 2 and 3 has a low probability for causing trouble. This is because use of Modes 2 and 3 constitutes less than $1 \%$ of the reactor operating time; the optimum void accident at full flow is the only reactivity insertion which has any safety significance in these two modes; full coolant flow in Modes 2 and 3 can only exist through misoperation; and the mechanism for introducing a sizable void has never been identified for any mode. With all this, the results of an optimum void in Modes 2 and 3 are of smaller consequence than in the unmodified Mode 1, where the results have been previously judged acceptable. ${ }^{1}$ Mode 1 was rerun as a check against results obtained 10 years agn. ${ }^{2}$ Case 12 of Table 1 most closely duplicates the conditions of Case 6 in ref. 2. The results are, in general, very close. The greatest disparity is in the hot-spot metal temperature, where the results shown in Table 1 of this report are $460^{\circ} \mathrm{F}$ higher than those previously achieved. This divergence stems from a difference in burnout modeling, wherein the previous simulation permitted return to nucleate boiling at reduced reactor power, whereas the model reported here permits no relief from steam blanketing 
following first achievement of film boiling. The former version is doubtless more realistic, particularly considering the SPERT experimental results cited in ref. 2 . The model of the present report must be considered extremely conservative. Even so, "burnout" heat flux was only achieved at the hot spot. This, by the conditions which give rise to it, must. be an extremely limited area spot, and the melting of such a spot would not only be of low probability, but could be handled if it occurred by the normal water processing system. This eventuality was discussed in ref. 2 , and results of the present simulation are in agreement. 
THIS PAGE

WAS INTENTIONALLY

LEFT BLANK 
APPENDIX A. COMPUTER MODEL DEVELOPMENT

\section{A1. Reactor Kinetics}

$$
\Lambda \dot{P}=(\rho-\beta) P+\Lambda \sum_{i=1}^{3} \lambda_{i} X_{i}
$$

and

$$
\Lambda \lambda_{i} \dot{X}_{i}=\lambda_{i} \beta_{i} P-\lambda_{i}\left(\Lambda \lambda_{i} x_{i}\right)
$$

where

$$
\begin{aligned}
& \Lambda=\text { mean prompt-neutron generation time, sec, } \\
& P=\text { nuclear power generation rate, } \\
& \rho=\text { reactivity, } \\
& \beta=\text { total delayed-neutron fraction, } \sum_{i=1}^{3} \beta_{i}, \\
& \lambda_{i}=\text { decay rate of the } i \text { th group of delayed neutrons, } \\
& X_{i}=\text { concentration of the } i \text { th delayed-neutron group, } \\
& \beta_{i}=\text { fraction of delayed neutrons of the } i t h \text { kind. }
\end{aligned}
$$

Two reduced groups of delayed neutrons are used, with $\beta_{1}=2.08 \times$ $10^{-3}, \lambda_{1}=0.02523, \beta_{2}=4.92 \times 10^{-3}$, and $\lambda_{2}=0.566$. These are chosen to satisfy the asymptotic behavior of the six-group transfer function; they provide excellent tracking of the six-group model. ${ }^{4}$

A third group of "delayed neutrons" is added to represent those neutrons entering the core by way of the reflector. For this group $\beta_{3}(\max )=0.153$ and $\lambda_{3}=2723$. Since $\rho$ for an isolated new core is 
-0.053 , and fully inserted control plates permit $3 \%$ of reflected neutrons to reach the core, $a B_{3}$ of 0.153 for reflected neutrons indicates an overal1 new-core shutdown margin of $0.053-0.03 \times 0.153=0.048$, or $4.8 \%$. The delay time for neutrons coming from the reflector is $2723^{-1}=367 \mu \mathrm{sec}$.

If the unreflected core generation time is set at $16.6 \mu \mathrm{sec}$, exposing enough of the reflector to a new core to bring the core to criticality yields a mean generation time of $0.947 \times 16.6+0.053 \times 367 \approx 35 \mu \mathrm{sec}$. For an old core, reactúvity is $10 \%$ luwer, ul 0.847 , meaning that to reach criticality. the rods must come all the way out to expose the full 0.153 worth of reflector $\left(B_{3}\right)$. In this condition, the mean generation time is $0.847 \times 16.6+0.153 \times 367 \approx 70 \mu \mathrm{sec}$. These values correspond to the neutron lifetimes given for new vs old cores, and hence properly account for the change of generation time with rod position in the HFIR.

True reactivity is fixed at -0.053 in the model, and effective reactivity changes due to rod motion are accomplished by altering $\beta_{3}$, the fractional return of neutrons from the reflector:

$$
\dot{\mathrm{P}}=\frac{\rho \mathrm{P}}{\Lambda}-\frac{\beta \mathrm{P}}{\Lambda}+\sum_{i=1}^{3} \lambda_{i} \mathrm{X}_{i}
$$

The variables that are to be computer amplifier outputs must be magnitude scaled in order for the amplifier outputs to range between 0 and $100 \mathrm{~V}$. We shall consider $100 \mathrm{~V}$ to be one machine unit. The ratiometer readout on the computer is in machine units so that its output ranges from 0 to 1.0 . The maximum value that each amplifier output variable may attain must be estimated, and a scale factor tor each established. The scale factor for a particular variable is the 
estimated maximum value of that variable. The magnitude of a particular variable, in physical units, is obtained by multiplying the variable value in machine units by its scale factor. For example, if we expect the nuclear power, P, to approach $2000 \mathrm{MW}$, but not to exceed $2000 \mathrm{MW}$, we would use a scale factor of 2000 for $P,\left(P_{\text {sf }}=2000\right)$. Then,

$$
P \text { in } M W=P_{\text {sf }} \times(P \text { in machine units }) .
$$

Writing Eq. (3) in machine unit variables $P, \Delta \rho$, and $\left(\Lambda \lambda_{1} X_{i}\right)$, taking $\rho_{0}$ as the initial reactivity, and letting $\Delta \rho$ represent the change due to void insertion and/or temperature coefficients:

$$
P_{s f} \dot{P}=\frac{\left(\rho_{o}+\rho_{s f} \Delta \rho\right) P_{s f} f^{P}}{\Lambda}-\frac{\beta P}{s f^{P}}+\frac{1}{\Lambda} \sum_{i=1}^{3} \Lambda \lambda_{i} X_{i}\left(\Lambda \lambda_{i} X_{i}\right)_{s f}
$$

and

$$
\dot{P}=\frac{\left(\rho_{0}+\rho_{s f} \Delta \rho\right) P}{\Lambda}-\frac{\beta P}{\Lambda}+\frac{1}{\Lambda P_{\text {sf }}} \sum_{i=1}^{3} \Lambda \lambda_{i} x_{i}\left(\Lambda \lambda_{i} x_{i}\right)_{s f} .
$$

Taking $\Lambda=16.6 \mathrm{\mu sec}$ and $\beta=B_{1}+\beta_{2}=0.007,{ }^{*}$ as previously introduced,

$$
\dot{\mathrm{p}}=60241\left(\rho_{\mathrm{sf}} \Delta \rho+\rho_{\mathrm{o}}\right) \mathrm{p}-421.7 \mathrm{P}+\frac{60241}{\mathrm{P}_{\mathrm{sf}}} \sum_{i=1}^{3} \Lambda \lambda_{i} \mathrm{X}_{i}\left(\Lambda \lambda_{i} \mathrm{X}_{i}\right)_{\mathrm{sf}}
$$

${ }^{*_{B}}{ }_{3}$ is not included as a component of $-\beta P$. The prompt-neutron loss due to input to $B_{3}$ is leakage, and, as such, it is implicitly included in the reactivity term $\rho_{0}$. 
As an example, we choose the following scale factors (the reason for these particular choices will be explained later):

$$
\rho_{\text {sf }}=0.0435 \Delta \rho
$$

and

$$
\begin{aligned}
& P_{\text {sf }}=2000 \mathrm{MW} . \\
& \left(\Lambda \lambda_{i} X_{i}\right)_{s f}=20 \mathrm{MW} \text { (assuming for the moment that the scale factor }
\end{aligned}
$$

is the same for all values of 1 ). We shall assume that we have a new, clean core, so $p=-0.053$. Equation (3a) becomes:

$$
\dot{\mathrm{P}}=60241(0.0435 \Delta \rho-0.053) \mathrm{P}-421.7 \mathrm{P}+\frac{60241(20)}{2000} \sum_{i=1}^{3} \Lambda \lambda_{i} \mathrm{X}_{i} \text {, }
$$

or

$$
\dot{\mathrm{P}}=2620.5 \Delta \rho \mathrm{P}-3614.5 \mathrm{P}+602.4 \sum_{i=1}^{3} \Lambda \lambda_{i} \mathrm{X}_{i}
$$

When the coefficients of the terms of a differential equation are large, a dynamically active system is indicated. It may be necessary to slow the response of the computer model in order to not exceed the dynamic response capabilities of some of the computer equipment, such as the strip chart recorder. On the other hand, very small coefficients indicate a dynamically sluggish system, and a speeded up computer model would be desired in the interest of saving computer time. Making the computer model dynamic response different from the dynamic response of the physical system being simulated is called "time scaling." Time scaling of a computer model may be accomplished by changing, by a common 
factor, the magnitudes of all the coefficients of all the terms of all the differential equations describing the system. Time scaling can also be accomplished by changing the size of all the capacitors in the feedbacks of all integrators by a common factor. Of course, a combination of the two methods may be used.

The large coefficients in Eq. (3b) indicate a need for time scaling. We shall make $25 \mathrm{sec}$ of machine time equivalent to $1 \mathrm{sec}$ of real system time (slowing down by a factor of 25):

$$
\begin{aligned}
& \dot{\mathrm{P}}=\frac{2620.5}{25} \Delta \rho \mathrm{P}-\frac{3614.5}{25} \mathrm{P}+\frac{602.4}{25} \sum_{i=1}^{3} \Lambda \lambda_{i} \mathrm{X}_{i} \\
& \dot{\mathrm{P}}=104.82 \Delta \rho \mathrm{P}-144.6 \mathrm{P}+24.1 \sum_{i=1}^{3} \Lambda \lambda_{i} \mathrm{X}_{i} .
\end{aligned}
$$

Incentive for additional time scaling is indicated by the large coefficients of this particular equation; however, we do not wish to unduly slow down some of the more sluggish portions of our system. In order to get the coefficients within the range of the computer coefficient devices, the size of the feedback capacitor for the integrator solving the $\dot{P}$ equation can be changed. We shall reduce this capacitor size by a factor of 1000 . Our computer equation now becomes

$$
\begin{aligned}
& \dot{P}=\frac{104.82}{1000} \Delta \rho \mathrm{P}-\frac{144.6}{1000} \mathrm{P}+\frac{24.1}{1000} \sum_{i=1}^{3} \Lambda \lambda_{i} \mathrm{X}_{1} \\
& \dot{\mathrm{P}}=0.1048 \Delta \rho \mathrm{P}-0.1446 \mathrm{P}+0.0241 \sum_{i=1}^{3} \Lambda \lambda_{i} \mathrm{X}_{i} .
\end{aligned}
$$


On the computer, amplifier number 020 solves the above equation for $P$. From Eq. (2) :

$$
\begin{gathered}
\Lambda \lambda_{1} \dot{\mathrm{X}}_{1}=\lambda_{1} \beta_{1} P-\lambda_{1}\left(\Lambda \lambda_{1} \mathrm{X}_{1}\right) \\
\cdot \\
\left(\Lambda \lambda_{1} \mathrm{X}_{1}\right)_{\text {sf }} \Lambda \lambda_{1} \dot{\mathrm{X}}_{1}=\lambda_{1} \beta_{1} \mathrm{P} \text { sf } \mathrm{P}-\lambda_{1}\left(\Lambda \lambda_{1} \mathrm{X}_{1}\right)_{\mathrm{sf}}\left(\Lambda \lambda_{1} \mathrm{X}_{1}\right) \\
\Lambda \lambda_{1} \dot{\mathrm{X}}_{1}=\frac{\lambda_{1} \beta_{1} \mathrm{P} \text { sf }}{\left(\Lambda \lambda_{1} \mathrm{X}_{1}\right)_{\text {sf }} P}-\lambda_{1}\left(\Lambda \lambda_{1} \mathrm{X}_{1}\right) .
\end{gathered}
$$

Substituting constant values and time scaling 25 to 1 :

$$
\begin{aligned}
& \Lambda \lambda_{1} \dot{\mathrm{X}}_{1}=\frac{0.02523\left(2.08 \times 10^{-3}\right) \mathrm{P}_{\text {sf }}}{\left(\Lambda \lambda_{1} \mathrm{X}_{1}\right)_{\mathrm{sf}} 25} \mathrm{P}-\frac{0.02523}{25}\left(\Lambda \lambda_{1} \mathrm{X}_{1}\right) \\
& \Lambda \lambda_{1} \dot{\mathrm{X}}_{1}=0.2099 \times 10^{-5} \frac{\mathrm{P}_{\text {sf }}}{\left(\Lambda \lambda_{1} \mathrm{X}_{1}\right)_{\text {sf }}} \mathrm{P}-1.0092 \times 10^{-3}\left(\Lambda \lambda_{1} \mathrm{X}_{1}\right) .
\end{aligned}
$$

These coefficients are too small to be set accurately on the coefficient devices. The gain through a coefficient device into an amplitier can be reduced a lactor of 17.667 by patch1ng 1 ts outpul lulu a X.1 input rather than into the summing junction. If we patch both inputs in this manner, the required settings of the coefficient devices themselves are increased by the same factor:

$$
\Lambda \lambda_{1} \dot{\mathrm{X}}_{1}=3.71 \times 10^{-5} \frac{\mathrm{P}_{\text {sf }}}{\left(\Lambda \lambda_{1} \mathrm{X}_{1}\right)_{\text {sf }}} \mathrm{P}-0.0178\left(\Lambda \lambda_{1} \mathrm{X}_{1}\right)
$$


Similarly, but without the factors of 17.667 :

$$
\begin{aligned}
& \Lambda \lambda_{2} \dot{\mathrm{X}}_{2}=\frac{\lambda_{2}{ }^{\beta}{ }^{P} \text { sf }}{\left(\Lambda \lambda_{2} \mathrm{X}_{2}\right)_{\text {sf }} 25} \mathrm{P}-\frac{{ }_{2}}{25}\left(\Lambda \lambda_{2} \mathrm{X}_{2}\right) \\
& \Lambda \lambda_{2} \dot{\mathrm{X}}_{2}=0.1114 \times 10^{-3} \frac{\mathrm{P} \text { sf }}{\left(\Lambda \lambda_{2} \mathrm{X}_{2}\right)_{\text {sf }}} \mathrm{P}-0.02264\left(\Lambda_{2} \mathrm{X}_{2}\right) .
\end{aligned}
$$

For the third group of "delayed neutrons," let $\beta_{3}=\beta_{3,0}+\Delta \beta_{3}$, where

$$
\begin{aligned}
& \beta_{3,0}=\text { delayed fraction due to the initial rod position, } \\
& \delta \beta_{3}=\text { change in } \beta_{3} \text { due to subsequent rod motion. }
\end{aligned}
$$

The "just critical" values of $B_{3,0}$ are 0.053 for a new, clean core and 0.153 for an end-of-life core. As previously stated, $\lambda_{3}=2723 \mathrm{sec}^{-1}$.

$$
\Lambda \lambda_{3} \dot{\mathrm{X}}_{3}=\left(\beta_{3,0}+\delta \beta_{3}\right) \lambda_{3} \mathrm{P}-\lambda_{3}\left(\Lambda \lambda_{3} \mathrm{X}_{3}\right)
$$

Consider the "just critical," new, clean-core case: $\beta_{3,0}=0.053$ and $\delta B_{3}=0$. The time scaling is 25 to 1 , and a capacitor 100 times smaller than standard is used.

$$
\begin{aligned}
\Lambda \lambda_{3} \dot{\mathrm{X}}_{3}= & \frac{0.053(2723) \mathrm{P}_{\text {sf }}}{\left(\Lambda \lambda_{3} \mathrm{X}_{3}\right)_{\text {sf }} \times 25 \times 100} \mathrm{P}+\frac{2723\left(\delta \beta_{3}\right)\left(\delta \beta_{3}\right)_{s f} P_{\text {sf }}}{\left(\Lambda \lambda_{3} \mathrm{X}_{3}\right)_{\text {sf }} \times 25 \times 100} \mathrm{P} \\
& -\frac{2723}{25 \times 100} \Lambda \lambda_{3} \mathrm{X}_{3}
\end{aligned}
$$




$$
\begin{aligned}
\Lambda \lambda_{3} \dot{\mathrm{X}}_{3}= & \frac{0.05773 \mathrm{P}_{\text {sf }}}{\Lambda \lambda_{3} \mathrm{X}_{3}{ }_{\text {sf }}} \mathrm{P}+1.0892 \frac{\left(\delta \beta_{3}\right)_{\text {sf }} \mathrm{P}_{\text {sf }}}{\left(\Lambda \lambda_{3} \mathrm{X}_{3}\right)_{\text {sf }}}\left(\delta \beta_{3}\right) \mathrm{P} \\
& -1.0892 \Lambda \lambda_{3} \mathrm{X}_{3}
\end{aligned}
$$

For the cases where we start with a new core in a subcritical state, the value of $\beta_{3,0}$ will be less than 0.053 . For instance, for the case where the reactor is $1 \%$ subcritical, $\dot{B}_{3,0}=0.053-0.01=0.043$. Equations (4), (5), and (6) are solved by amplifiers 221,231 , and 240 , respectively.

As an example, write Eqs. (3a), (4), (5), and (6) using the following scale factors:

$$
\begin{aligned}
& P_{\text {of }}=2000 \\
& \left(\Lambda \lambda_{1} \mathrm{x}_{1}\right)_{\mathrm{gf}}-\left(\Lambda \lambda_{2} \mathrm{x}_{2}\right)_{\text {of }}=20 \\
& \left(\Lambda_{3^{2}} \mathrm{x}_{3}\right)_{\mathrm{sf}}=200 \\
& \left(\Lambda \lambda_{3}\right)_{\text {sf }}=0.1 \\
& n_{\text {st }}=0.0435 \\
& \dot{\mathrm{P}}=0.1048 \Delta \rho \mathrm{P}-0.1446 \mathrm{P}+0.0241 \Lambda \lambda_{1} \mathrm{X}_{1} \\
& +0.0241 \Lambda \lambda_{2} \mathrm{x}_{2}+0.2410 \Lambda \lambda_{3} \mathrm{x}_{3}
\end{aligned}
$$




$$
\begin{aligned}
& \Lambda \lambda_{1} \dot{\mathrm{X}}_{1}=0.0037 \mathrm{P}-0.0178 \Lambda \lambda_{1} \mathrm{X}_{1} \\
& \Lambda \lambda_{2} \dot{\mathrm{X}}_{2}=0.01114 \mathrm{P}-0.02264 \Lambda \lambda_{2} \mathrm{X}_{2} \\
& \Lambda \lambda_{3} \dot{\mathrm{X}}_{3}=0.5773 \mathrm{P}+1.0892 \delta \beta_{3} \mathrm{P}-1.0892 \Lambda \lambda_{3} \mathrm{X}_{3}
\end{aligned}
$$

\section{A2. Safety Rod Drive System}

The safety rod acceleration starts at a value of $4 \mathrm{G}$, decreases linearly to $1 \mathrm{G}$ over the first 6 in. of travel, and then remains at $1 \mathrm{G}$ until the end of the insertion ( $\mathrm{G}$ is the value of the acceleration due to gravity, $32.2 \mathrm{ft} / \sec ^{2}$ ):

$$
\begin{array}{ll}
\frac{d^{2} S}{d t^{2}}=4 G-0.5 G S & (0 \leqslant s \leqslant 6 \text { in. }) \\
\frac{d^{2} S}{d t^{2}}=G & (s>6 \text { in. }),
\end{array}
$$

where $S$ is rod displacement in inches. For $S \leqslant 6$ in.:

$$
\begin{aligned}
\dot{S}_{\text {Jf }} \quad \ddot{S} & =4 G-0.5 G S_{\varepsilon f} S \\
\ddot{S} & =\frac{4 G}{\dot{S}_{s f}}-\frac{0.5 G S_{s f}}{\dot{S}_{s f}} \mathrm{~s} \\
& =\frac{4(32.2)}{\dot{S}_{\text {sf }}}-\frac{(0.5)(32.2) S_{s f}}{\dot{S}_{\text {sf }}}
\end{aligned}
$$


Let $\dot{\mathrm{S}}_{\mathrm{sf}}=50 \mathrm{ft} / \mathrm{sec}$ and $\mathrm{s}_{\text {sf }}=24 \mathrm{in}$. Time scaling is $25: 1$, as previously chosen:

$$
\begin{aligned}
\ddot{S} & =\frac{4(32.2)}{50(25)}-\frac{(0.5)(32.2)(24)}{50 \times 25} \mathrm{~S} \\
& =0.1030-0.3091 \mathrm{~S} \quad(\mathrm{~S} \leqslant 6 \mathrm{in} .) . \\
\ddot{\mathrm{S}} & =\frac{\mathrm{G}}{\dot{\mathrm{S}}_{\text {sf }}}=\frac{32.2}{50 \times 25}=0.02576 \quad(\mathrm{~S}>6 \mathrm{in.}) .
\end{aligned}
$$

Numerical values shown are to be taken as coefficlent settings.

The output of amplifier 230 is $\dot{S}$ and the output of amplifier 250 is $S$. The coefficient between $\dot{S}$ and $S=\frac{50 \mathrm{ft} / \mathrm{sec} \times 12 \mathrm{in} \cdot / \mathrm{Ft}}{24 \times 25}=1.0$. Taking Fig. 7.3.7 of ref. 5 as a starting point, one finds that the change in reactivity per inch of $3-0 f-4$ safety rod displacement may be closely approximated by the following:

$$
\begin{aligned}
& \frac{\partial \mu}{\partial x}=0.00058 / 1 \mathrm{n} . \quad(0<s \leqslant 2.54 \text { in. }) \\
& \frac{\partial p}{\partial x}=0.00333 / \text { in. } \quad(2.54<s \leqslant 12.11 \text { in. }) \\
& \frac{\partial \rho}{\partial x}=0.000714 / \text { in. }(12.11<s \leqslant 20 \text { in. }) .
\end{aligned}
$$

As established earlier, changes in reactivity due to control plate motion come as the result of altering the fractional reflection of leakage neutrons. This is recognized in the model by creating an additional "delayed-neutron" group, wherein $\delta \beta_{3}$ contributes to reactivity with a time constant of $\lambda_{3}^{-1}=367 \mu \mathrm{sec}$. The $\partial \rho / \partial x^{\prime}$ s above are therefore directly translatable to $\partial \beta_{3} / \partial x^{\prime} s$. 
For the first $2.54 \mathrm{in} .,\left(\delta \beta_{3}\right)_{a}=0.00058 \mathrm{~S}$, reaching 0.001473 at $2.54 \mathrm{in}$.

From 2.54 to 12.11 in.,

$$
\begin{aligned}
\left(\delta \beta_{3}\right)_{b} & =0.00333(S-2.54)+0.001473 \\
& =0.00333 S-0.006993,
\end{aligned}
$$

reaching 0.03337 at $\mathrm{S}=12.11$ in.

From 12.11 to 20 in.,

$$
\begin{aligned}
\left(\delta B_{3}\right)_{c} & =0.000714(S-12.11)+0.03337 \\
& =0.000714 S+0.02473
\end{aligned}
$$

reaching 0.03900 at $\mathrm{S}=20 \mathrm{in}$.

$$
\left(\delta \beta_{3}\right)_{a}=0.00058 \mathrm{~S} \text { is left permanently connected, with increments }
$$
switched in for $\left(\delta \beta_{3}\right)_{b}$ and $\left(\delta \beta_{3}\right)_{c}$, as needed.

$$
\left(\delta B_{3}\right)_{\text {sf }}=0.1 ; s_{s f}=24
$$

Coefficient settings:

$$
\begin{aligned}
& \delta \beta_{3}=\frac{0.00058(24)}{0.1}=0.1392 \quad \text { (coefficient 244) } \\
& \left(\delta \beta_{3}\right)_{b}-\left(\delta B_{3}\right)_{a} \text { is generated in amplifier } 012 \text { and is added to }\left(\delta \beta_{3}\right)_{a} \text { in } \\
& \text { amplifier } 022 \text { between } S=2.54 \text { and } 12.11 \mathrm{in} .
\end{aligned}
$$




$$
\begin{aligned}
\left(\delta \beta_{3}\right)_{b}-\left(\delta \beta_{3}\right)_{a} & =0.00333 S-0.006993-0.00058 \mathrm{~S} \\
& =0.00275 \mathrm{~S}-0.006993 \\
\text { Coeff } 006 & =\frac{0.00275(24)}{0.1}=0.6607 \\
\text { Coeff } 004 & =\frac{0.006993}{0.1}=0.0699
\end{aligned}
$$

$\left(\delta \beta_{3}\right)_{c}-\left(\delta \beta_{3}\right)_{a}$ is generated in amplifier 013 and is added to $\left(\delta \beta_{3}\right)_{a}$ in ampllfler 022 fǜï $3>12.11$ in.

$$
\begin{aligned}
& \left(\delta \beta_{3}\right)_{c}-\left(\delta B_{3}\right)_{a}=0.000714 S+0.02473-0.00058 S=0.000134 S+0.02473 \\
& \text { Coeff } 007=\frac{0.000134(24)}{0.1}=0.0322 \\
& \text { Coeff } 005=\frac{0.02473}{0.1}=0.2473
\end{aligned}
$$

The variable $\delta \beta_{3}$ is the output of summing amplifier 022 .

For the start-up accident cases, amplifier 022 has an additlunal input due to continuous rod withdrawal. Amplifier 261 generates changes in $\delta \beta_{3}$ as a result of continuous rod withdrawal, and is input to amplifier 022 (instead of amplifier 011 as shown) for these cases.

Let $\frac{d}{d t}\left(\delta \beta_{3}\right)_{r w}=R_{r w}$,

where

$$
\left(\delta \beta_{3}\right)_{\mathrm{rw}}=\text { reactivity due to rod withdrawal in a start-up accident, }
$$




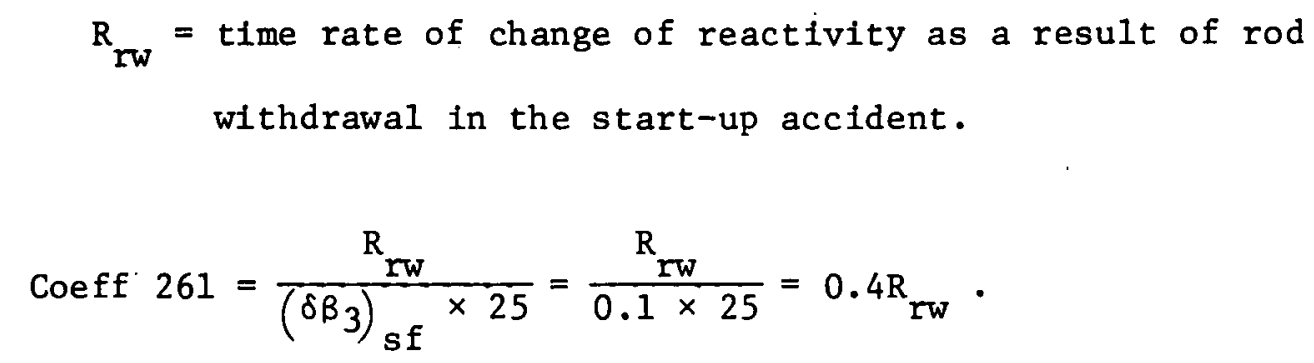

A3. Reactivity Changes

$$
\Delta \rho_{t}=\alpha_{f}\left(\bar{T}_{f}-\bar{T}_{f o}\right)+\alpha_{w}\left(\bar{T}_{w}-\bar{T}_{w o}\right)
$$

where

$$
\begin{aligned}
& \Delta \rho_{t}=\text { change in reactivity due to changes in the fuel and water } \\
& \text { temperatures combined, } \\
& \alpha_{f}=\text { fuel temperature coefficient of reactivity, } \\
& \mathrm{T}_{\text {fo }}=\text { initial steady-state fuel temperature, } \\
& \alpha_{w}=\text { coolant water coefficient of reactivity, } \\
& \mathrm{T}_{\text {wo }}=\text { initial steady-state coolant temperature, } \\
& \Lambda_{t}=\frac{\alpha_{f} \bar{T}_{f s f} \bar{T}_{f}}{\left(\Delta \rho_{t}\right)_{s f}}-\frac{\alpha_{f} \bar{T}_{f o}}{\left(\Delta \rho_{t}\right)_{s f}}+\frac{\alpha_{w} \bar{T}_{w s f} \bar{T}_{w}}{\left(\Delta \rho_{t}\right)_{s f}}-\frac{\alpha_{w} \bar{T}_{w o}}{\left(\Delta \rho_{t}\right)_{s f}} \text {, } \\
& \overline{\mathrm{T}}_{\text {wgf }}=500 \text { and } \overline{\mathrm{T}}_{\mathrm{fsf}}=2000 ; \alpha_{\mathrm{f}}=-1.6 \times 10^{-5} /{ }^{\circ} \mathrm{F} \text {, and } \\
& \alpha_{\mathrm{w}}=-8.7 \times 10^{-5} \text { * } \\
& \left(\Delta \rho_{t}\right)_{s f} \text { is chosen such that the } \overline{\mathrm{I}}_{\mathrm{w}} \text { coefficient in the equation }
\end{aligned}
$$
is equal to 1 .

*High-temperature values are from Table 6, ref. 2. Low-temperature values are used for startup accident runs. 
Therefore,

$$
\left(\Delta \rho_{t}\right)_{\text {sf }}=\alpha_{w} \bar{T}_{\text {wsf }}=8.7 \times 10^{-5} \times 500=0.0435
$$

It will be recalled that this value was used (without explanation) in developing Eq. (3b). Therefore,

$$
\begin{aligned}
\Delta \rho_{t}= & \frac{1.6 \times 10^{-5} 2000}{0.0435} \overline{\mathrm{T}}_{\mathrm{f}}+1.0 \overline{\mathrm{T}}_{\mathrm{w}}-\frac{1.6 \times 10^{-5} \overline{\mathrm{T}}_{\mathrm{fo}}}{0.0435} \\
& -\frac{8.7 \times 10^{-5} \overline{\mathrm{T}}_{\mathrm{wo}}}{0.0435} \\
= & 0.7356 \overline{\mathrm{T}}_{\mathrm{f}}+1.0 \overline{\mathrm{T}}_{\mathrm{w}}-3.678 \times 10^{-4} \overline{\mathrm{T}}_{f o}-0.0020 \overline{\mathrm{T}}_{\text {wo }}, \text { (12a) }
\end{aligned}
$$

where

$$
\begin{aligned}
& \overline{\mathrm{T}}_{\text {fo }}=222^{\circ} \mathrm{F} \text { and } \overline{\mathrm{T}}_{\text {wo }}=154.5^{\circ} \mathrm{F}, \\
& \Delta \rho_{t}=0.7356 \overline{\mathrm{T}}_{\mathrm{f}}+\overline{\mathrm{T}}_{\mathrm{w}}-0.3907 .
\end{aligned}
$$

Summing amplificr 011 is used to solve this equation. The reactivity change due to void insertion is also summed Into duplifler 011. The equation for void induced reactivity is

$$
\frac{\mathrm{d}\left(\Delta \rho_{\mathrm{v}}\right)}{\mathrm{dt}}=\mathrm{R}_{\mathrm{v}} \text {, }
$$

where

$$
\Delta \rho_{v}=\text { change in reaclivily due to void insertion, }
$$




$$
\mathrm{R}_{\mathrm{v}}=\text { time rate of change of reactivity due to void insertion. }
$$

Going to the machine equations,

$$
\left(\Delta \rho_{v}\right)_{s f} \frac{d\left(\Delta \rho_{v}\right)}{d t}=R_{v}
$$

Time scaling by our factor of 25 , and letting $\left(\Delta \rho_{v}\right)_{s f}=0.1$ :

$$
\frac{d\left(\Delta \rho_{v}\right)}{d t}=0.4 R_{v} \text {. }
$$

Amplifier 261 is used to solve this equation. The equation for amplifier 011 becomes:

$$
\begin{aligned}
\Delta \rho & =\Delta \rho_{\mathrm{t}}+\Delta \rho_{\mathrm{v}} \\
(\Delta \rho)_{\mathrm{sf}} & =\left(\Delta \rho_{\mathrm{t}}\right)_{\mathrm{sf}}=\alpha_{\mathrm{w}} \overline{\mathrm{T}}_{\mathrm{wsf}}=0.0435 \\
(\Delta \rho)_{\mathrm{sf}} \Delta \rho & =\left(\Delta \rho_{\mathrm{t}}\right)_{\mathrm{sf}} \Delta \rho_{\mathrm{t}}+\left(\Delta \rho_{\mathrm{v}}\right)_{\mathrm{sf}} \Delta \rho_{\mathrm{v}} \\
\Delta \rho & =\Delta \rho_{\mathrm{t}}+\frac{\left(\Delta \rho_{\mathrm{v}}\right)_{\mathrm{sf}}}{(\Delta \rho)_{\mathrm{sf}}} \Delta \rho_{\mathrm{v}}
\end{aligned}
$$

For the case where

$$
\begin{aligned}
\left(\Delta \rho_{\mathrm{v}}\right)_{\mathrm{sf}} & =0.1, \\
\Delta \rho & =\Delta \rho_{\mathrm{t}}+\frac{0.1}{0.0435} \Delta \rho_{\mathrm{v}}=\Delta \rho_{\mathrm{t}}+2.2989 \Delta \rho_{\mathrm{v}} .
\end{aligned}
$$


A3. Heat Transfer

The heat transfer equations for a typical region of the core are the following:

$$
C_{f} \frac{d T_{f}}{d t}=a P-h A\left(T_{f}-T_{w}\right)
$$

and

$$
c_{w} \frac{d T_{w}}{d L}=b P-\frac{C_{w}}{T}\left(T_{w}-T_{i, n}\right)+h A\left(T_{f}-T_{w}\right),
$$

where

$$
\begin{aligned}
& C_{f}=\text { total fuel plate heat capacity, Btu/ }{ }^{\circ} \mathrm{F} \text {, } \\
& \mathrm{T}_{\mathrm{f}}=\text { average fuel surface temperature in region, }{ }^{\circ} \mathrm{F} \text {, } \\
& a=\text { fraction of total power generated in the fuel, } \\
& \mathrm{Btu} / \mathrm{sec} \text { in fue1/MW total, } \\
& P=\text { rate of total heat generation, } M W \text {, } \\
& h=\text { overall heat transfer coefficient between the fuel and the } \\
& \text { coolant, beu sec } \operatorname{sit}^{-1} n^{-1} \text {, } \\
& \mathrm{A}=\text { total heat transfer area of region, } \mathrm{ft}^{2} \text {, } \\
& \mathrm{T}_{\mathrm{w}}=\text { average coolant temperacure in the region, }{ }^{\circ} \mathrm{F} \text {, } \\
& \mathrm{C}_{\mathrm{W}}=\text { coolant heat capacity (total for the region), } \mathrm{Btu} /{ }^{\circ} \mathrm{F} \text {, } \\
& b=\text { fraction of total heat generated in the coolant, Btu/sec in } \\
& \text { coolant/MN total, } \\
& \tau=\text { the residence time of the coolant in the reglun, suc, } \\
& \mathrm{T}_{\text {in }}=\text { coolant temperature at the region entrance, }{ }^{\circ} \mathrm{F} \text {. }
\end{aligned}
$$




$$
\begin{aligned}
& T_{f s c} \frac{d T_{f}}{d t}=\frac{a P_{s f}}{C_{f}} P-\frac{h A T_{f f f}}{C_{f}} T_{f}+\frac{h A T_{w S f}}{C_{f}} T_{w} . \\
& T_{w s f} \frac{d T_{w}}{d t}=\frac{b P_{s f}}{C_{s}} P-\frac{T_{w S f}}{\tau} T_{w}+\frac{1}{\tau} T_{\text {In }}+\frac{h A T_{f s f}}{C_{w}} T_{f}-\frac{h A T_{w S f}}{C_{w}} T_{w} .
\end{aligned}
$$

With time scaling 25 to 1 : .

$$
\begin{aligned}
\frac{d T_{f}}{d t}= & \frac{a P_{\text {sf }}}{25 C_{f} T_{f s c}} P-\frac{h A}{25 C_{f}} T_{f}+\frac{h A T_{w s f}}{25 C_{f} T_{f s f}} T_{w}, \\
\frac{d T_{w}}{d t}= & \frac{b P_{s f}}{25 C_{w} T_{w s f}} P-\frac{1}{25 \tau} T_{w}+\frac{1}{25 \tau T_{w s f}} T_{i n} \\
& +\frac{h A T_{\text {fsf }}}{25 C_{w} T_{\text {wsf }}} T_{f}-\frac{h A}{25 C_{w}} T_{w} .
\end{aligned}
$$

The values for the constants in Eqs. (15) and (16) were obtained from Table 4, page 14 of ref. 2; or they were deduced from the values given in the table. As an example, we shall develop the equation for a nominal region in a beginning of life core.

The pertinent given information is:

$$
\begin{aligned}
\mathrm{a} & =\frac{\mathrm{aP}}{\mathrm{P}}=\frac{92,400 \mathrm{Btu} / \mathrm{sec}}{100 \mathrm{MW}}=924 \mathrm{Btu} \mathrm{sec}^{-1} \mathrm{MW}^{-1}, \\
\mathrm{~b} & =27.21 \mathrm{Btu} / \mathrm{sec} \mathrm{MW}, \\
\mathrm{C}_{\mathrm{f}} & =35.7 \mathrm{Btu} /{ }^{\circ} \mathrm{F},
\end{aligned}
$$


32

$$
\begin{aligned}
& \mathrm{T}_{\text {fo }}=222^{\circ} \mathrm{F}, \\
& \mathrm{T}_{\text {wo }}=\frac{189+120}{2}=154.5^{\circ} \mathrm{F}, \\
& \mathrm{T}_{\text {in }}=120^{\circ} \mathrm{F} .
\end{aligned}
$$

Therefore,

$$
\begin{aligned}
\dot{\mathrm{T}}_{\mathrm{f}} & =\frac{92400}{35.7}-\frac{\mathrm{hA}}{35.7}(222-154.5) \text { for steady-stale operation. } \\
\dot{\mathrm{T}}_{\mathrm{f}} & =0 \text { at steady state; therefore, } \\
67.5(\mathrm{hA}) & =92400 \\
\mathrm{hA} & =1369 \mathrm{Btu} \mathrm{sec}^{-1}{ }^{\circ} \mathrm{F}^{-1} . \\
\tau & =\frac{0.0397}{2}=0.01985 \mathrm{sec} \\
\dot{\mathrm{T}}_{\mathrm{w}}= & \frac{2721+92400}{\mathrm{C}_{\mathrm{w}}}-\frac{1}{0.01985}(154.5-120)=0 \text { at steady state; }
\end{aligned}
$$

therefore,

$$
C_{w}=\frac{95121 \times 0.01985}{34.5}=54.73 \frac{\mathrm{Btu}}{{ }^{\circ} \mathrm{F}} .
$$

Use the following scale factors:

$$
\begin{aligned}
\mathrm{P}_{\text {sf }} & =2000 \mathrm{MW}, \\
\mathrm{T}_{\text {fsf }} & =2000^{\circ} \mathrm{F}, \\
\mathrm{T}_{\text {fSf }} & =500^{\circ} \mathrm{F} .
\end{aligned}
$$


Equation (15) becomes

$$
\begin{aligned}
& \dot{\mathrm{T}}_{\mathrm{f}}=\frac{(924)(2000)}{(25)(35.7)(2000)} \mathrm{P}-\frac{1369}{(25)(35.7)} \mathrm{T}_{\mathrm{f}}+\frac{(1369)(500)}{(25)(35.7)(2000)} \mathrm{T}_{\mathrm{w}} \\
& \dot{\mathrm{T}}_{\mathrm{f}}=1.0353 \mathrm{P}-1.5338 \mathrm{~T}_{\mathrm{f}}+0.3834 \mathrm{~T}_{\mathrm{w}}
\end{aligned}
$$

This equation is solved by amplifier 271 .

Equation (16) becomes:

$$
\begin{aligned}
\dot{\mathrm{T}}_{\mathrm{w}}= & \frac{(27.21)(2000)}{(25)(54.73)(500)} \mathrm{P}-\frac{1}{(25)(0.01985)} \mathrm{T}_{\mathrm{w}}+\frac{1}{(25)(0.01985)(500)}(120) \\
& \quad+\frac{(1369)(2000)}{(25)(54.73)(500)} \mathrm{T}_{\mathrm{f}}-\frac{(1369)}{(25)(54.73)} \mathrm{T}_{\mathrm{w}} \\
= & 0.0795 \mathrm{P}-2.0151 \mathrm{~T}_{\mathrm{w}}+0.4836+4.0019 \mathrm{~T}_{\mathrm{f}}-1.0005 \mathrm{~T}_{\mathrm{w}} \\
= & 0.0795 \mathrm{P}-3.0156 \mathrm{~T}_{\mathrm{w}}+4.0019 \mathrm{~T}_{\mathrm{f}}+0.4836
\end{aligned}
$$

This equation is solved by amplifier 241 .

The pertinent information for the "hot streak" is as follows:

$$
\begin{aligned}
& a=\frac{a P}{100}=\frac{132500}{100}=1325 \mathrm{Btu} \mathrm{sec}^{-1} \mathrm{MW}^{-1}, \\
& \mathrm{~b}=\frac{\mathrm{bP}}{100}=\frac{2775}{100}=27.75 \mathrm{Btu} \mathrm{sec}^{-1} \mathrm{MW}^{-1,}, \\
& \mathrm{C}_{\mathrm{f}}=35.7 \mathrm{Btu} /{ }^{\circ} \mathrm{F},
\end{aligned}
$$




$$
\begin{aligned}
\mathrm{T}_{\text {fo }} & =337^{\circ} \mathrm{F}, \\
\mathrm{T}_{\text {wo }} & =257^{\circ} \mathrm{F}, \\
\mathrm{T}_{\text {in }} & =121^{\circ} \mathrm{F}, \\
\tau & =0.0403 \mathrm{sec} \cdot \text { (Hot streak temperature is at the outlet.) }
\end{aligned}
$$

Setting $\dot{T}_{f}=0$ for steady-state, 100-MW operation:

$h A(337-257)=132500$

$\mathrm{hA}=1656 \mathrm{Btu} \mathrm{sec}^{-1}{ }^{\circ} \mathrm{F}^{-1}$

Use the following scale factors:

$$
\begin{aligned}
P_{s f} & =2000 \mathrm{MW}, \\
T_{f s f} & =4000^{\circ} \mathrm{F}, \\
\left(\Delta \mathrm{T}_{s t}\right)_{s f} & =\text { to be determined, } \\
T_{w s f} & =\text { to be determined. } \\
\text { Let } \Delta \mathrm{T}_{s t} & =\mathrm{T}_{\mathrm{t}}-\mathrm{T}_{\mathrm{w}} . \\
\dot{\mathrm{T}}_{\mathrm{f}} & =\frac{(1325)(2000)}{(25)(35.7)(4000)} \mathrm{P}-\frac{1656(\Delta \mathrm{T} s t}{(25)(35.7)(4000)} \Delta \mathrm{T}_{s t}
\end{aligned}
$$

Chonse $\left(\Delta T_{S \tau}\right)_{\text {sf }}$ such that the coefficient of the second term is equal to unity. 


$$
\begin{aligned}
& \frac{1656\left(\Delta \mathrm{T}_{\text {st }}\right)_{\text {sf }}}{(25)(35.7)(4000)}=1, \\
& \left(\Delta \mathrm{T}_{\text {st }}\right)_{\mathrm{sf}}=2155.8, \\
& \dot{\mathrm{T}}_{\mathrm{f}}=0.7423 \mathrm{P}-\Delta \mathrm{T}_{\text {st }} .
\end{aligned}
$$

Setting $\dot{\mathrm{T}}_{\mathrm{W}}=0$ for steady-state, 100-MW operation:

$$
\begin{gathered}
2775-\frac{C_{w}}{0.02015}(257-121)+132500=0, \\
\frac{136}{0.0403} C_{w}=132500+2775, \\
C_{w}=40.085 \mathrm{Btu} /{ }^{\circ} \mathrm{F} .
\end{gathered}
$$

Coefficients for the $\mathrm{T}_{\mathrm{w}}$ equation are so large as to require "gainof-10" inputs in order to reduce settings by a factor of 10 . This is achieved by use of a one-tenth size feedback capacitor, and accounts for the (10) in the denominator of the following equation:

$$
\begin{aligned}
\dot{\mathrm{T}}_{\mathrm{w}}= & \frac{(27.75)(2000)}{(40.085)(25)(10) \mathrm{T}_{\text {wsf }}} \mathrm{P}+\frac{(1656)(2155.8)}{(40.085)(25)(10) \mathrm{T}_{\text {wsf }}} \Delta \mathrm{T}_{\text {st }} \\
& -\frac{1\left(\mathrm{~T}_{\text {wsf }}\right)}{0.0403\left(\mathrm{~T}_{\text {wsf }}\right)(25)(100)} \mathrm{T}_{\mathrm{w}}+\frac{1(121)}{0.0403\left(\mathrm{~T}_{\text {wsf }}\right)(25)(10)}
\end{aligned}
$$


Choose $T_{\text {wsf }}$ such that the coefficients of the second term will be 1:

$$
\begin{aligned}
& \frac{(1656)(2155.8)}{(40.085)(25)(10) T_{\text {wsf }}}=1 \\
& \mathrm{~T}_{\text {wsf }}=356.24^{\circ} \mathrm{F} \text {, } \\
& \dot{T}_{w}-0.01 \overline{5} 6 \bar{P}+\Delta T_{s t}=0.04 \overline{9}{ }^{\prime}{ }_{w}+0.0 .337 . \\
& \Delta T_{\text {st }}=\frac{4000 \mathrm{~T}_{\mathrm{f}}}{2155.8}-\frac{356.24}{2155.8} \mathrm{~T}_{\mathrm{w}} \\
& =1.8555 \mathrm{~T}_{\mathrm{f}}-0.1652 \mathrm{~T} \mathrm{w}_{\mathrm{w}} .
\end{aligned}
$$

Equations (19) (20), and (21) are solved by amplifiers 310,331 , and 321 , respectively.

The hot-sput information consistent with this example is

$$
\begin{aligned}
\mathrm{a} & =\frac{\mathrm{aP}}{100}=\frac{242300}{100}=2423 \mathrm{Btu} \mathrm{sec}^{-1} \mathrm{MW}^{-1}, \\
\mathrm{C}_{\mathrm{f}} & =35.7 \mathrm{Btu} /{ }^{\circ} \mathrm{F}, \\
\mathrm{T}_{\text {fo }} & =407^{\circ} \mathrm{i}, \\
\mathrm{T}_{\text {wo }} & =257^{\circ} \mathrm{F} .
\end{aligned}
$$


As in the scaling for the hot streak,

$$
T_{\text {fsf }}=4000^{\circ} \mathrm{F} \text {. }
$$

The heat is transferred from the fuel at the hot spot to the hotstreak water. For steady-state operation at $100 \mathrm{MW}$ :

$$
\mathrm{C}_{\mathrm{f}} \dot{\mathrm{T}}_{\mathrm{f}}=0=242300-\mathrm{hA}(407-257) \text {. }
$$

Therefore,

$$
\begin{aligned}
& \mathrm{hA}=1615.3 \mathrm{Btu} \mathrm{sec}^{-1} \circ_{\mathrm{F}}^{-1} . \\
& \text { Let } \Delta \mathrm{T}_{\mathrm{SP}}=\mathrm{T}_{\mathrm{f}}-\mathrm{T}_{\mathrm{w}}, \\
& \dot{\mathrm{T}}_{\mathrm{f}}=\frac{(2423)(2000)}{(35.7)(4000)(25)} \mathrm{P}-\frac{1615.3\left(\Delta \mathrm{T}_{\mathrm{sp}}\right)_{\mathrm{Sf}}}{(35.7)(4000)(25)} \Delta \mathrm{T}_{\mathrm{sp}} .
\end{aligned}
$$

Choose $\left(\Delta \mathrm{T}_{\mathrm{sp}}\right)_{\text {sf }}$ such that the coefficient of the second term is equal to 1 :

$$
\begin{aligned}
& \frac{1615.3\left(\Delta \mathrm{T}_{\mathrm{sp}}\right)_{\mathrm{sf}}}{(35.7)(4000)(25)}=1, \\
& \left(\Delta \mathrm{T}_{\mathrm{sp}}\right)_{\mathrm{sf}}=2210^{\circ} \mathrm{F}, \\
& \dot{\mathrm{T}}_{\mathrm{f}}=1.3574 \mathrm{P}-\Delta \mathrm{T}_{\mathrm{sp}}, \\
& \Delta \mathrm{T}_{\mathrm{sp}}=\frac{4000}{2210} \mathrm{~T}_{\mathrm{f}}-\frac{356.24}{2210} \mathrm{~T}_{\mathrm{w}}, \\
& \Delta \mathrm{T}_{\mathrm{sp}}=1.8099 \mathrm{~T}_{\mathrm{f}}-0.1612 \mathrm{~T}
\end{aligned}
$$


Equations (22) and (23) are solved by amplifiers 311 and 340 respectively.

Should the heat flux at any location reach the burnout value of

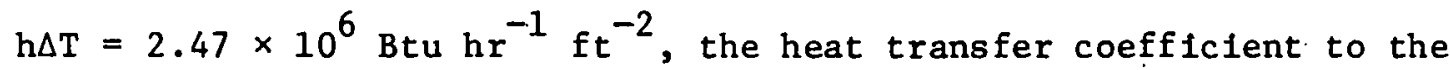
water is assumed to drop to 0 . In the runs described here, this burnout condition is only encountered at the hot spot.

As shown previously, under steady-state, hot-spot conditions, and for comparison purposes assuming the arca involved th he the whole core,

$$
\begin{aligned}
(\mathrm{hA})_{\mathrm{sp}} & =1615.3 \mathrm{Btu} \mathrm{sec}-1{ }^{\circ} \mathrm{F}^{-1}=5.815 \times 10^{6} \mathrm{Btu} \mathrm{hr}^{-1}{ }^{\circ} \mathrm{F}^{-1}, \\
\Delta \mathrm{T}_{\mathrm{sp}} & =407^{\circ}-257^{\circ}=150^{\circ} \mathrm{F}, \\
\mathrm{A} & =\text { heat transfer area of whole core }=428.8 \mathrm{ft}^{2} \text { (ref. 5). }
\end{aligned}
$$

So

$$
\mathrm{h}=\mathrm{hA} / \mathrm{A}=5.815 \times 10^{6} / 428.8=13,560 \mathrm{Btu} \mathrm{hr} \mathrm{ft}^{-2}{ }^{2} \mathrm{~F}^{-1} .
$$

This coefficient will produce the burnout heat flux at a fuel-water $\Delta \mathrm{T}$ of $(\mathrm{h} \Delta \mathrm{T}) \mathrm{b}_{\mathrm{o}} / \mathrm{h}=2.47 \times 10^{6} / 13,560=182.2^{\circ} \mathrm{F}$.

Comparator 330 matches hot-spot $\Delta \mathrm{T}$ against this burnout $\Delta \mathrm{T}$ of $182.2^{\circ} \mathrm{F}$. When the burmult $\Delta \overline{\mathrm{T}}$ is reached, f11p rlap 301 1o oet through gate 311 , and electronic switch $360 \mathrm{~B}$ opens, thereby stopping heat transfer from hot-spot fuel to the water.

$$
\text { For }\left(\Delta \mathrm{T}_{\mathrm{sp}}\right)_{\mathrm{sf}}=2210^{\circ}, \Delta \mathrm{T}_{\text {ref }}=182.2 / 2210=0.0824 \text {. Amplifier } 300
$$
generates this reference $\Delta \mathrm{T}$. 
APPENDIX B. VARIATIONS OF PARAMETERS

Procedures similar to those just completed may be used to determine the coefficients of the describing equations for any consistent set of system parameters.

The analog computer patching schematic is shown in Fig. 1A. 


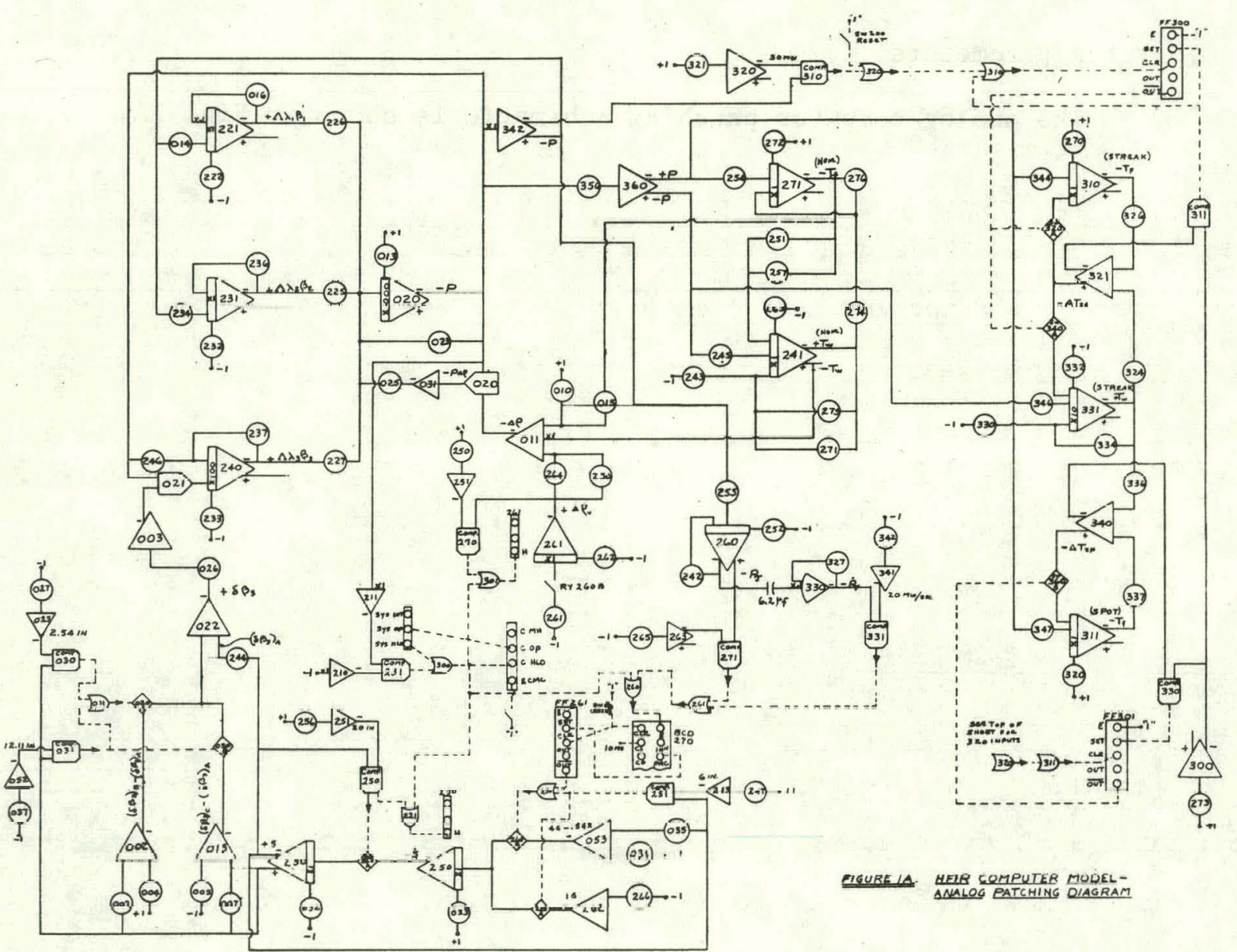

Fig. 1A. HFIR computer model, analog patching diagram. 


\section{REFERENCES}

1. F. T. Binford, T. E. Cole, and E. N. Cramer, The High Flux Isotope Reactor Accident Analysis, ORNL-3573 (Apr11 1967).

2. R. D. Cheverton, O. W. Burke, and T. E. Cole, HFIR Transients and Reactivity Accountability, ORNL-TM-1747 (January 18, 1967).

3. R. S. Stone, HEIR Response to Void Swept Into Flux Trap, ORNL CF-60-8-39 (August 10, 1960).

4. R. E. Skinner and E. R. Cohen, Reduced Delayed Neutron Group Representations, NAA-SR-3204 (Apri1 1, 1959).

5. F. T. Binford, T. E. Cole, and E. N. Cramer, The High Flux Isotope Reactor, A Functional Description, Vol. 1A, ORNL-3572 (Rev. 2), (May 1968). 
THIS PAGE

\section{WAS INTENTIONALLY LEFT BLANK}


INTERNAL DISTRIBUTION

1. J. L. Anderson

2. D. S. Asquith

3. F. T. Binford

4. R. S. Booth

5. C. J. Borkowsk1

6-8. 0. W. Burke

9. C. D. Cagle

10. R. D. Cheverton

11. T. E. Cole

12. B. L. Corbett

13. J. A. Cox

14. S. J. Ditto

15. D. N. Fry
16. H. N. Hill

17-21. R. V. McCord

22. I. C. Oakes

23. C. W. Ricker

24. G. S. Sadowsk1

25. W. H. Sides

26. T. M. Sims

27-29. R. S. Stone

30. K. W. West

31-32. Central Research L1brary

33. Document Reference Section

34-36. Laboratory Records Department

37. Laboratory Records, ORNL R. C.

38. ORNL Patent Office

EXTERNAL DISTRIBUTION

39. Director, Research \& Technical Support Division, ERDA-ORO

40-66. Technical Information Center 